\title{
TGF- $\beta_{1}$ genotype and accelerated decline in lung function of patients with cystic fibrosis
}

Peter D Arkwright, Steven Laurie, Maurice Super, Vera Pravica, Martin J Schwarz, A Kevin Webb, Ian V Hutchinson

\begin{abstract}
Background-Polymorphisms in transforming growth factor (TGF)- $\beta_{1}$ associated with variations in cytokine levels are linked to fibrosis in a number of tissues. However, the contribution of this cytokine to organ fibrosis in patients with cystic fibrosis is presently unclear. This study was undertaken to examine the association between TGF- $\beta_{1}$ gene polymorphisms and the development of pulmonary dysfunction in patients with cystic fibrosis.
\end{abstract}

Methods-Polymorphisms in the TGF- $\beta_{1}$ gene defining amino acids of codons 10 and 25 were determined by ARMS-PCR using DNA stored on 171 Caucasian patients who were homozygous for the $\Delta F 508$ mutation of the cystic fibrosis transmembrane conductance regulator (CFTR) gene. Clinical information on the patients was obtained from medical records.

Academic Unit of Child Health, University of

Manchester, St Mary's Hospital, Manchester M13 0JH, UK

P D Arkwright

School of Biological

Sciences, University of Manchester,

Manchester M13 9PT,

UK

S Laurie

V Pravica

I V Hutchinson

Department of Clinical Genetics, Royal Manchester Children's Hospital, Manchester M27 4HA, UK

M Super

M Schwarz

Bradbury Cystic

Fibrosis Unit,

Wythenshawe

Hospital, Manchester

M23 9LT, UK

A K Webb

Correspondence to: Dr P D Arkwright email:mdmfspda fs1.scg.man.ac.uk

Received 8 September 1999 Returned to authors 11 November 1999 Revised manuscript received 21 December 1999 Accepted for publication 20 January 2000
Results-Patients with cystic fibrosis of a TGF- $\beta_{1}$ high producer genotype for codon 10 had more rapid deterioration in lung function than those with a TGF- $\beta_{1}$ low producer genotype. The relative risk of accelerated decline in forced expiratory volume in one second $\left(\mathrm{FEV}_{1}\right)$ to $50 \%$ predicted and forced vital capacity (FVC) to $70 \%$ predicted of patients with a high producer genotype was 1.74 (95\% CI 1.11 to 2.73$)$ compared with 1.95 (95\% CI 1.24 to 3.06) for those with a low producer genotype.

Discussion-TGF- $\beta_{1}$ genotypes may have a role in mediating pulmonary dysfunction in patients with cystic fibrosis. Further work is required to determine whether inhibition of TGF- $\beta_{1}$ activity in these patients may slow disease progression.

(Thorax 2000;55:459-462)

Keywords: cystic fibrosis; transforming growth factor (TGF) $-\beta_{1}$; polymorphisms; lung function tests

Cystic fibrosis is the most common fatal inherited condition in the western world. Despite advances in the medical management of cystic fibrosis over the last three decades, there are still a number of unexplained differences in its clinical course, especially in the rate of development of respiratory failure of patients who appear to have the same CFTR genotype, degree of bacterial colonisation, and compliance with medication. ${ }^{12}$ In this study we have tested the hypothesis that this difference may be due partly to inherited variation in the ability of patients to express the profibrotic cytokine, transforming growth factor (TGF)- $\beta_{1}$.

TGF- $\beta_{1}$ is produced by many cells throughout the body and promotes the proliferation of fibroblasts and the deposition of collagen. ${ }^{34}$ Production of TGF- $\beta_{1}$ varies between individuals and partly depends on polymorphisms in the TGF- $\beta_{1}$ gene at positions +869 and +915 encoding codons 10 and $25 .^{5-8}$ The bi-allelic polymorphism, either a $\mathrm{T}$ or $\mathrm{C}$ in the DNA sequence at position +869 (relative to the major transcription start site), changes the amino acid at codon 10 from leucine to proline. Similarly, the bi-allelic polymorphism, either a $\mathrm{G}$ or $\mathrm{C}$ at position +915 , results in the amino acid at codon 25 being either arginine or proline. For both polymorphisms the allele encoding proline is associated with lower TGF- $\beta_{1}$ synthesis in vitro and in vivo.

In human lung tissue TGF- $\beta_{1}$ produced by bronchial epithelial cells stimulates fibroblasts to proliferate in vitro. ${ }^{9}$ Previous animal and human studies have shown that high TGF- $\beta_{1}$ producers develop significantly more lung fibrosis in response to a number of inflammatory triggers such as radiation, ${ }^{10}$ chemotherapy, ${ }^{11}$ and lung transplantation. ${ }^{5}$ Little is known about the role of TGF- $\beta_{1}$ in cystic fibrosis. Examination of lung tissue in two patients with cystic fibrosis showed strong immunohistological staining of inflammatory tissue using an antibody against this cytokine. ${ }^{12}$ In this study we have investigated the correlation between high TGF- $\beta_{1}$ production and pulmonary dysfunction in cystic fibrosis by determination of polymorphisms in the TGF- $\beta_{1}$ gene.

\section{Methods}

PATIENTS AND CLINICAL RECORDS

The Department of Clinical Genetics at the Royal Manchester Children's Hospital, Manchester has stored DNA from all patients with cystic fibrosis in the North West region of the United Kingdom who have been referred for genetic mutation testing over the last two decades. Data from 171 patients who attended one of three major cystic fibrosis units in Manchester (Royal Manchester Children's Hospital, Booth Hall Children's Hospital or Wythenshawe Hospital) were examined. Clinical information was obtained from hospital notes and physiotherapy records in which formal lung function tests were regularly recorded. At the time of blood collection consent had been obtained to use their DNA for studies which 
Table 1 Frequencies of TGF- $\beta_{1}$ polymorphisms

\begin{tabular}{|c|c|c|c|}
\hline \multicolumn{2}{|c|}{ TGF- $\beta_{1}$ polymorphisms } & \multirow[t]{2}{*}{ Controls $(n=107)$} & \multirow[t]{2}{*}{$C F$ patients $(n=171)$} \\
\hline+869 (codon 10) & +915 (codon 25) & & \\
\hline \multicolumn{4}{|l|}{ Allele frequencies } \\
\hline $\mathrm{T}$ & Any & $139(65 \%)$ & $224(66 \%)$ \\
\hline C & Any & $75(35 \%)$ & $118(34 \%)$ \\
\hline Any & G & $193(90 \%)$ & $319(93 \%)$ \\
\hline Any & $\mathrm{C}$ & $21(10 \%)$ & $23(7 \%)$ \\
\hline \multicolumn{4}{|c|}{ Genotype frequencies } \\
\hline $\mathrm{T} / \mathrm{T}^{\star}$ & - & $44(41 \%)$ & $67(39 \%)$ \\
\hline $\mathrm{T} / \mathrm{C}$ & - & $51(48 \%)$ & $90(53 \%)$ \\
\hline $\mathrm{C} / \mathrm{C}$ & - & $12(11 \%)$ & $14(8 \%)$ \\
\hline- & $\mathrm{G} / \mathrm{G}^{\star}$ & $87(81 \%)$ & $149(87 \%)$ \\
\hline- & $\mathrm{G} / \mathrm{C}$ & $19(18 \%)$ & $21(12 \%)$ \\
\hline- & $\mathrm{C} / \mathrm{C}$ & $1(1 \%)$ & $1(1 \%)$ \\
\hline $\mathrm{T} / \mathrm{T}$ & $\mathrm{G} / \mathrm{G}$ & $44(41 \%)$ & $66(39 \%)$ \\
\hline $\mathrm{T} / \mathrm{C}$ & $\mathrm{G} / \mathrm{G}$ & $38(36 \%)$ & $72(42 \%)$ \\
\hline $\mathrm{C} / \mathrm{C}$ & $\mathrm{G} / \mathrm{G}$ & $5(5 \%)$ & $11(6 \%)$ \\
\hline $\mathrm{T} / \mathrm{T}$ & $\mathrm{G} / \mathrm{C}$ & $0(0 \%)$ & $1(0 \%)$ \\
\hline $\mathrm{T} / \mathrm{C}$ & $\mathrm{G} / \mathrm{C}$ & $13(12 \%)$ & $17(10 \%)$ \\
\hline $\mathrm{C} / \mathrm{C}$ & $\mathrm{G} / \mathrm{C}$ & $6(6 \%)$ & $3(2 \%)$ \\
\hline $\mathrm{T} / \mathrm{T}$ & $\mathrm{C} / \mathrm{C}$ & $0(0 \%)$ & $0(0 \%)$ \\
\hline $\mathrm{T} / \mathrm{C}$ & $\mathrm{C} / \mathrm{C}$ & $0(0 \%)$ & $1(0 \%)$ \\
\hline $\mathrm{C} / \mathrm{C}$ & $\mathrm{C} / \mathrm{C}$ & $1(1 \%)$ & $0(0 \%)$ \\
\hline
\end{tabular}

${ }^{\star}$ TGF- $\beta_{1}$ high producer genotypes ${ }^{5}$; all others are TGF- $\beta_{1}$ low producer genotypes.

would enhance scientific knowledge of their condition. Polymorphism frequencies were compared with those of 107 healthy laboratory workers and renal transplant donors analysed previously in our laboratory. ${ }^{6}$

All 171 patients were Caucasian and homozygous for the $\Delta \mathrm{F} 508 \mathrm{CFTR}$ gene mutation; $45 \%$ were male with ages ranging from 6 to 54 years (mean (SD) 23 (9) years). Forty three $(25 \%)$ had died at a mean (SD) of $22(8)$ years

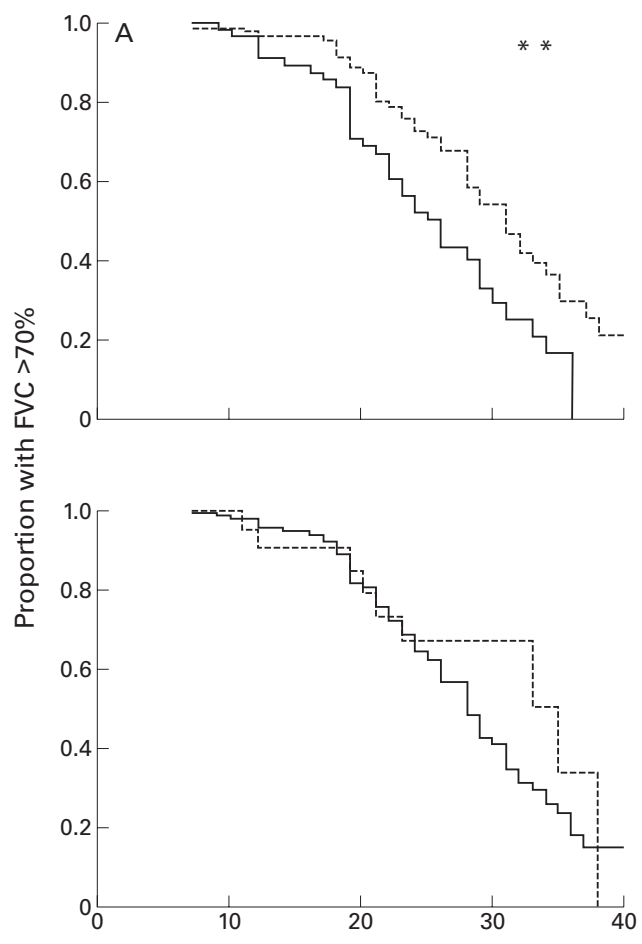

Age (years)

Figure 1 Proportion of patients with (A) FVC $>70 \%$ predicted and (B) $F E V_{1}>50 \%$ predicted with increasing age for polymorphisms in TGF- $\beta$, codon 10 and codon 25. Cases were censored from the analysis after the age of final follow up. Continuous line $=T G F-\beta_{1}$ high producer genotype; broken line $=T G F-\beta_{1}$ low producer genotype. ${ }^{\star} p<0.01,{ }^{\star}{ }^{\star} p<0.005$, Kaplan-Meier analysis. (range 6-50) and 85 (50\%) had developed respiratory failure with forced expiratory volume in one second $\left(\mathrm{FEV}_{1}\right)$ of $<50 \%$ predicted at 20 (7) years (range $5-35$ ). 15\% of patients had cirrhosis with portal hypertension (heterogeneous appearance of liver, dilated portal vein, and splenomegaly on abdominal ultrasound scan) and the same percentage had insulin dependent diabetes. Only $4 \%$ of patients had both cirrhosis and diabetes.

TGF- $\beta_{1}$ GENE POLYMORPHISM STUDIES

Archived DNA used in this study had been extracted from $5 \mathrm{ml}$ whole blood using standard methods. The technique used to genotype individual samples for the two TGF- $\beta_{1}$ alleles under investigation was an amplification refractory mutation system-polymerase chain reaction (ARMS-PCR) method using primers already described. ${ }^{7}$

\section{STATISTICAL ANALYSIS}

Survival analysis was carried out by KaplanMeier and Cox regression analysis using the SPSS statistical package. Medians and 95\% confidence intervals (CI) are given.

\section{Results}

TGF- $\beta_{1}$ POLYMORPHISM FREQUENCIES

The relative frequencies of the two polymorphisms of TGF- $\beta_{1}$ gene are shown in table 1 and are similar to those found in healthy adults. ${ }^{6}$ There was no skewing of the distribution of these polymorphisms in patients who had died or in those with $\mathrm{FEV}_{1}<50 \%$ predicted, with cirrhosis, or with diabetes.

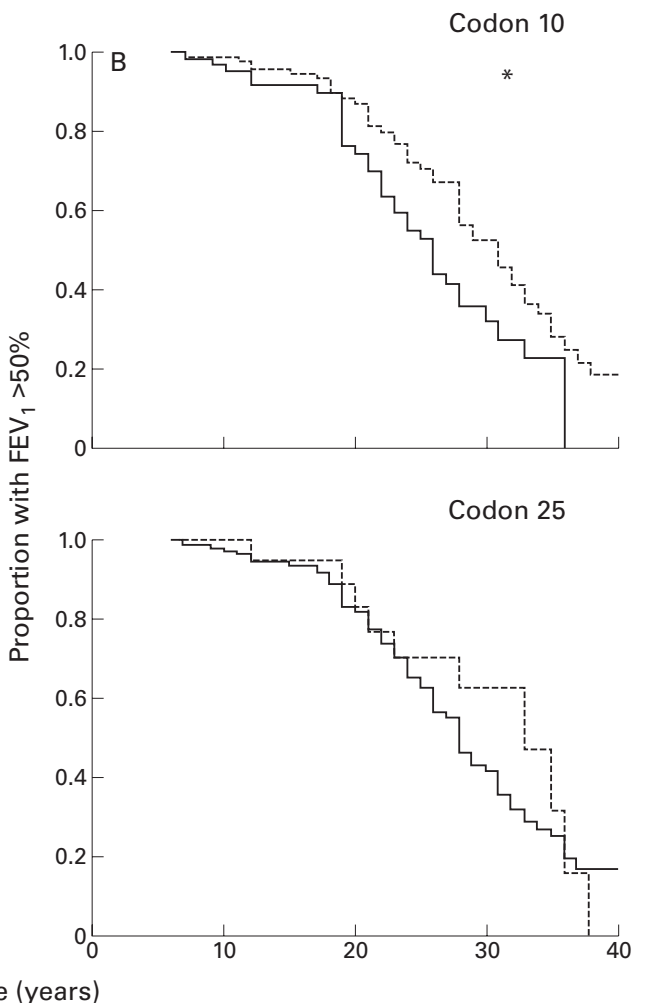


Table 2 Hazard ratios and 95\% confidence intervals (CI) for more rapid deterioration in FEV to $<50 \%$ predicted and FVC to $<70 \%$ predicted with high producer TGF- $\beta_{1}$ genotype

\begin{tabular}{|c|c|c|c|c|c|c|}
\hline & \multicolumn{3}{|l|}{$F E V_{1}$} & \multicolumn{3}{|l|}{$F V C$} \\
\hline & Hazard ratio & $95 \% C I$ & pvalue & Hazard ratio & $95 \% C I$ & $p$ value \\
\hline \multicolumn{7}{|l|}{ Codon 10} \\
\hline "High" & 1.74 & 1.11 to 2.73 & $<0.02$ & 1.95 & 1.24 to 3.06 & $<0.005$ \\
\hline "Low" & 1.00 & & & 1.00 & & \\
\hline \multicolumn{7}{|l|}{ Codon 25} \\
\hline "High" & 1.05 & 0.68 to 2.74 & NS & 1.40 & 0.70 to 2.80 & NS \\
\hline "Low" & 1.00 & & & 1.00 & & \\
\hline \multicolumn{7}{|c|}{ Codons $10+25$} \\
\hline "High" & 1.71 & 1.10 to 2.69 & $<0.02$ & 1.91 & 1.21 to 2.99 & $<0.005$ \\
\hline "Low" & 1.00 & & & 1.00 & & \\
\hline
\end{tabular}

NS = not significant.

MORTALITY

The average age at death or lung transplantation of patients who had the TGF- $\beta_{1}$ high producer genotype for codons 10 and/or 25 was not significantly different from patients with a low producer genotype using Kaplan-Meier statistical analysis.

RESPIRATORY INSUFFICIENCY

Patients with the TGF- $\beta_{1}$ high producer genotype for codon 10, but not codon 25, developed a forced vital capacity (FVC) of $<70 \%$ predicted on average five years younger (mean 26 (range 23-29) years) than patients with a TGF- $\beta_{1}$ low producer genotype (mean 31 (range 28-34) years; fig 1 ). The relative risk of patients with a high producer genotype having a reduced FVC of $<70 \%$ predicted at a younger age was double that of patients with a low producer genotype (hazard ratio 1.95 (95\% CI 1.24 to 3.06 ), $\mathrm{p}<0.005$; table 2). Patients with a high producer TGF- $\beta_{1}$ genotype also developed severe obstructive disease $\left(\mathrm{FEV}_{1}<50 \%\right)$ and respiratory failure at a significantly lower age than patients with a low producer genotype (hazard ratio 1.74 (95\% CI 1.11 to 2.73 ), $\mathrm{p}<0.02$; fig 1 ). Of those with an FVC of $<70 \%$ predicted, $86 \%$ also had an $\mathrm{FEV}_{1}$ of $<50 \%$ predicted $\left(\mathrm{p}<0.000001 ; \chi^{2}\right.$ test).

There were no significant differences between the proportion of patients with Pseudomonas aeruginosa or Burkholderia cepacia isolated from sputum culture and non-colonised patients $(\mathrm{n}=21(12 \%))$ with a TGF- $\beta_{1}$ high producer genotype. The TGF- $\beta_{1}$ high producer genotype was also not associated with a shorter interval between lung colonisation and development of pulmonary insufficiency $\left(\mathrm{FEV}_{1}\right.$ $<50 \%$ predicted).

\section{Discussion}

In this study we have shown that, in patients with cystic fibrosis, the TGF- $\beta_{1}$ codon 10 high producer genotype is associated with a more rapid deterioration in lung function. This is in agreement with studies of patients following lung transplantation ${ }^{513}$ and in animal models of lung injury following radiation $^{10}$ and chemotherapy ${ }^{11}$ where inherent production of high levels of TGF- $\beta_{1}$ are associated with more severe lung fibrosis and more rapid deterioration in lung function. High levels of TGF- $\beta_{1}$ have also been associated with increased fibro- sis in the liver of patients with autoimmune hepatitis ${ }^{14}$ and animals models of both liver and kidney fibrosis. ${ }^{15-17}$

Lung disease in patients with cystic fibrosis is characterised by both airway obstruction and interstitial fibrosis. The standard way of measuring the progress of lung disease is by spirometric testing at each outpatient attendance. We found that the risk of $\mathrm{FEV}_{1}$ falling below 50\% predicted and FVC falling below $70 \%$ predicted at a significantly younger age in patients with a TGF- $\beta_{1}$ codon 10 high producer genotype was almost double that of patients with a low producer genotype; $86 \%$ of our patients had both an $\mathrm{FEV}_{1}$ of $<50 \%$ predicted and an FVC of $<70 \%$ predicted. One would expect a stronger correlation between polymorphisms in the profibrotic TGF- $\beta_{1}$ cytokine gene and lung fibrosis (restrictive lung disease) than with airway obstruction. However, because of the close correlation between obstructive and restrictive disease in patients with cystic fibrosis, it may be difficult to dissect out the relative association between the TGF- $\beta_{1}$ genotype and these two elements of lung disease, even in a prospective study using full lung function tests to assess the degree of restrictive lung disease.

No correlation was found between the TGF- $\beta_{1}$ codon 25 genotype and measures of survival or lung function. As the population is skewed markedly towards a high producer genotype $(87 \%)$, the number of patients in the low producer genotype group was small $(\mathrm{n}=$ 22) which may have reduced the power of the study to detect differences between the groups. However, in a previous study with a similar sample size in which the association between TGF- $\beta_{1}$ polymorphisms and histological evidence of pulmonary fibrosis in patients undergoing lung transplantation was examined, we found a significant increase in the proportion of patients with high producer genotype for both codons 25 and 10. The difference was more significant for codon $10(\mathrm{p}<0.004)$ than for codon 25 ( $\mathrm{p}<0.02) .^{5}$ The fact that histological examination provided a much more accurate means of assessing fibrosis than lung function tests may provide part of the explanation for these differences.

In summary, TGF- $\beta_{1}$ high producer genotypes predict a group of cystic fibrosis patients who will develop more rapid pulmonary disease. Further work is required to determine 
whether blocking the effects of this cytokine may retard the progression of lung disease. The authors thank Dr G Hambleton, Professor T J David, and
Dr L Patel who work in the CF units in Manchester for allowDr L Patel who work in the CF units in Manchester for allowing us to study their patients. We are grateful to Geraldine
Malone and Nicola Andrew for technical advice. Statistical Malone and Nicola Andrew for technical advice. Statistical
advice obtained from Dr K Bennett, CRC Paediatric and advice obtained from Dr K Bennett, CRC Paediatric and
Familial Cancer Group, University of Manchester was also greatly appreciated.

1 Cystic Fibrosis Genotype-Phenotype Consortium. Correlation between genotype and phenotype in patients with cystic fibrosis. N Engl f Med 1993;329:1308-13.

Zielenski J, Tsui LC. Cystic fibrosis: genotypic and phenotypic variations. Ann Rev Genetics 1995;29:777-807.

3 Roberts AB, Lamb LC, Newton DL, et al. Transforming growth factors: isolation of polypeptides from virally and chemically transformed cells by acid/ethanol extraction. Proc Natl Acad Sci USA 1980;77:3494-8.

4 Ignotz R, Massague J. Transforming growth factor- $\beta$ stimulates the expression of fibronectin and collagen and their incorporation into the extracellular matrix $f$ Biol Chem 1986;261:4337.

5 Awad MR, El-Gamel A, Hasleton P, et al. Genotypic variation in the transforming growth factor- $\beta 1$ gene. Transplantation 1998;66:1014-20

6 Perrey C, Pravica V, Sinnott PJ, et al. Genotyping for polymorphisms in interferon- $\gamma$, interleukin-10, transforming growth factor- $\beta 1$ and tumour necrosis factor- $\alpha$ : a teching growth factor- $\beta 1$ and tumour necrosis factor-

7 Perrey C, Turner SJ, Pravica V, et al. ARMS-PCR methodologies to determine IL-10, TNF- $\alpha$, TNF- $\beta$ and TGF- $\beta 1$ gene polymorphisms. Transplant Immunol 1999;7:127-8.
8 Grainger DJ, Heathcote K, Chiano M, et al. Genetic control of the circulating concentration of transforming growth of the circulating concentration of transforming
factor type beta 1. Hum Mol Genet 1999;8:93-7.

9 Nakamura Y, Tate L, Ertl RF, et al. Bronchial epithelial cells regulate fibroblast proliferation. Am $\mathcal{F}$ Physiol 1995;269. L377-87.

10 Franko AJ, Sharplin J, Ghahary A, et al. Immunochemical localization of transforming growth factor $\beta$ and tumour necrosis factor $\alpha$ in the lungs of fibrosis-prone and "non-fibrosing" mice during the latent period and early phase after irradiation. Radiat Res 1997;147:245-56.

11 Phan SH, Kunkel SL. Lung cytokine production in bleomycin-induced pulmonary fibrosis. Exp Lung Res 1992;18:29-43.

12 Corrin B, Butcher D, McAnulty BJ, et al. Immunohistochemical localization of transforming growth factor-beta 1 in the lungs of patients with systemic sclerosis, cryptogenic fibrosing alveolitis and other lung disorders. Histopathology 994;24:145-50.

13 El-Gamel A, Awad M, Sim E, et al. Transforming growth actor-beta-1 and lung allograft fibrosis. Eur $\mathcal{F}$ Cardiothorac Surg 1998;13:424-30.

14 Bayer EM, Herr W, Kanzler S, et al. Transforming growth factor-beta-1 in autoimmune hepatitis: correlation of liver tissue expression and serum levels with disease activity. $\mathcal{F}$ Hepatol 1998;28:803-11.

15 Qi Z, Atsuchi N, Ooshima A, et al. Blockade of type beta transforming growth factor signaling prevents liver fibrosis and dysfunction in the rat. Proc Natl Acad Sci USA 1999;96:2345-9.

16 Kanzler S, Lohse AW, Keil A, et al. TGF- $\beta 1$ in liver fibrosis: an inducible transgenic mouse model to study liver fibrinoan inducible transgenic mouse model to study

17 Kopp JB, Factor VM, Mozes M, et al. Transgenic mice with increased plasma levels of TGF- $\beta 1$ develop progressive renal disease. Lab Invest 1996;74:991-1003. 